\title{
Frontal Anterior Laryngectomy with Epiglottic Reconstruction (Tucker's Operation): Oncologic and Functional Results
}

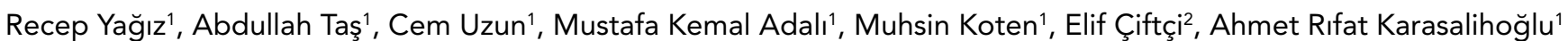

'Department of Ear, Nose and Throat, Faculty of Medicine, Trakya University, Edirne, Turkey

${ }^{2}$ Department of Ear, Nose and Throat, Çorlu State Hospital, Tekirdağ, Turkey

\begin{abstract}
Objective: To evaluate functional and oncological results of patients who were treated with frontal anterior laryngectomy with epiglottic reconstruction (Tucker's operation).

Material and Methods: From September 1985 to November 2009, 58 patients whose early glottic carcinomas were operated on with Tucker's operation. The time of decannulation, nasogastric tube removal, hospitalization and oncological results were analyzed. Acoustic analysis and Voice Handicap Index (VHI) were used to evaluate vocal function.

Results: The mean time for decannulation and nasogastric tube removal were $11.8 \pm 7.6$ and $15.4 \pm 4.4$ days, respectively. The mean duration of hospital stay was $19.3 \pm 6.1$ days. It was found that early decannulation significantly reduced patient decannulation and hospitalization time. The 5 -year overall and cause-specific actuarial survival rates were $81.5 \%$ and $96.9 \%$, respectively. The 10 -year overall and cause-specific survival rates were $67 \%$ and $92.3 \%$, respectively. The 5 -year local and nodal control rates were $95.4 \%$ and $95.2 \%$, respectively. The mean values for jitter, shimmer and noise-to-harmonic ratio were $8.10 \pm 5.59 \%, 16.60 \pm 5.81 \%$ and $0.51 \pm 0.23$, respectively, and these scores showed a significant increase. Total VHI score and subscale scores except VHI-emotional noted that patients had a mild level of vocal disability.
\end{abstract}

Conclusion: Tucker's operation is one of the preferred techniques in the treatment of early glottic carcinoma with its high oncologic success rate and satisfactory functional results.

Key Words: Laryngeal neoplasms, carcinoma, squamous cell, laryngectomy

Received: 11.01.2011 Accepted: 16.05.2011

\section{Introduction}

There are various treatment modalities for early glottic cancer. It has been treated by radiotherapy, transoral excision with or without laser or open partial laryngectomy (1). The basic goals of partial laryngectomy techniques used in the surgical treatment of laryngeal cancer are to provide complete surgical resection in compliance with the oncologic principles and in addition to maintain deglutition, phonation and respiration, which are the physiologic functions of the lar$y n x$ (2). To achieve these goals in the surgical management of glottic cancer, many laryngeal reconstructive techniques have been described. One of these techniques is frontal anterior laryngectomy with epiglottic reconstruction described by Tucker et al. (3) in 1979 for treatment of laryngeal carcinoma involved glottic region. This technique allows removal of the two vocal cords, one arytenoid cartilage (when required), anterior commissure with thyroid cartilage, anterior part of both false vocal cords, and of $1 \mathrm{~cm}$ of subglottis $(4,5)$. Oncological and functional results of this technique are limited to a few reports in the English literature (5-7). The purpose of the present study was to evaluate the functional and oncological results of 58 patients who were treated with frontal anterior laryngectomy with epiglottic reconstruction (Tucker's operation).

\section{Material and Methods}

In this retrospective study, we analyzed 58 patients with early-stage glottic carcinoma who underwent the Tucker procedure between September 1985 and November 2009. There were 56 male and 2 female patients with a median age of 56.5 years (range, $40-78$ years). All patients were preoperatively examined by suspension microlaryngoscopy and most of them (51 patients who were operated after 1992) were endoscopically examined using $30^{\circ}$ and $70^{\circ}$ telescopes to assess the possible involvement of the ventricles, the anterior commissure, and the subglottic region. None of the patients had received previous radiation therapy. Two patients had been treated by surgical procedure (cordectomy=one patient and horizontal glottectomy=one patient). The arytenoid cartilage on the tumor-bearing side was resected in 13 patients, and both arytenoid cartilages were preserved in the remaining 45 patients. Functional ipsilateral neck dissection 
was performed in 6 patients. All of the patients had squamous cell carcinoma with glottic localization. Patients who did not have squamous cell carcinoma were excluded. Patients who had adjuvant chemoradiotherapy after surgery, salvage treatment (total laryngectomy or radiotherapy) due to locoregional recurrences and functional failures (who could not be decannulated), were not included in the analysis of vocal and late swallowing function. While 39 of 58 patients had T1 glottic tumors, the remaining 19 patients suffered from T2 glottic tumors. Eleven (T1a) out of 39 cases with T1 glottic tumors had tumors with one cord-involvement, and reached the anterior commissure and did not impair the movement of the cord, while the remaining 28 cases (T1b) had tumors involving the anterior commissure partially reaching the opposite cord or covering both cords, extending from the anterior commissure without impairing the movement of the cords.

Voice exercises were started on the fifth day post-operatively and swallowing and movement of the base of tongue exercises were started on the seventh day. In our study, 29 patients were operated on up to 2003 , nasogastric feeding tube was removed after patients started to swallow liquid nutrition without having any problems, and in the following days, decannulation was performed. However, early decannulation (during the first postoperative week if possible) was preferred in 29 patients operated on after 2003, and the nasogastric tube was removed in the following days with no difficulty in swallowing.

Vocal and late swallowing functions could be evaluated in 26 patients who had a follow-up for more than one year after surgery. Vocal functions were evaluated by acoustic analysis and voice handicap index (VHI). Computerized Speech Lab Model 4500 from Kay Elemetrics Corp. and Multi Dimensional Voice Program Model 5105 (NJ, USA) was used to perform objective acoustic analyses. Fundamental frequency (Fo), jitter $\%$, shimmer \%, noise-to-harmonic ratio (NHR) and maximum phonation time (MPT) parameters were assessed.

The $\mathrm{VHI}$ is a questionnaire devised by Jacobson et al. (8) whereby the patient evaluates his own voice. The Turkish version of the $\mathrm{VHI}$ was validated previously (9). The $\mathrm{VHI}$ is a $30-$ item questionnaire with three subgroups -functional, physical and emotional- each containing 10 items. In each subgroup, a point of 8 or over showed deteriorated voice quality, and a total score, ranging between a minimum of 0 and a maximum of 120 , is obtained. Vocal disabilities were classified as mild (less than 30$)$, moderate (31-60), severe (61-90), and very severe (91-120) (10).

Acoustic analysis data of 10 individuals ( 9 males and $1 \mathrm{fe}-$ male) aged between 54 and 75 (median age, 60 years) with no voice-related complaints, who had previously been reported by our department with the same equipment, were used as the control group data (11).

The scale formed by Leipzing (12) and Pearson (13) (0: none; 1: occasional cough, no clinical problem; 2: constant cough, worsening with meals or swallow; 3: pulmonary complications) was used to evaluate the late postoperative aspiration.

\section{Statistical analysis}

Analysis of functional results such as decannulation time, nasogastric tube removal, and hospital stay was performed by the Independent-samples t-test. The Kaplan-Meier analysis was used to evaluate overall survival, cause of specific survival, local control, and nodal control. The parametric $\chi^{2}$ test and the nonparametric Mann-Whitney $U$ test were used for the analysis of qualitative and quantitative variables, respectively. Mann-Whitney $U$ test was used to compare vocal function results of the study groups. Spearman correlation test was used for correlation analysis. A p value below 0.05 was considered statistically significant. All functional results were expressed as mean \pm standard deviation.

\section{Results}

A great majority of patient smoked (93.1\%) and drank alcohol (65.5\%). Only 3 patients (5.2\%) were non-smokers and non-drinkers. The dysphonia symptom was the basic complaint during initial referral of patients. The median symptom duration was 5 months (range, 1 month-6 year). Three of the patients had repeat biopsies (twice in 1 case, 3 times in 1 case, and 4 times in 1 case) for diagnostic purposes. No patient died in the immediate postoperative period. Postoperative complications/problems are shown in Table 1. One patient with aspiration pneumonia was managed successfully with antibiotic therapy. Postoperative histopathologic examination showed a tumor free of resection margin in 50 patients $(86.2 \%)$, a positive surgical margin in four patients $(6.9 \%)$ and close-contiguity margin in four patients (6.9\%). Only one patient with positive surgical margin (in addition with cartilage invasion) underwent adjuvant chemoradiotherapy. Other patients with positive or close-contiguity margins were followed closely. There were no metastatic lymph nodes in all neck specimens. In the follow-up period, complications were seen between three and 15 months. Granulation or polypoid tissue formations in the endolaryngeal region were among the most common problems encountered during postoperative follow-up. To eliminate local recurrence in the early period, these lesions were excised by microlaryngoscopy in 7 out of 9 patients during follow-up period. Laryngeal synechia or stenosis was seen in two patients. In one patient, this was confined to the epiglottis only, and was easily treated by microlaryngoscopy. In the other patient, an endolaryngeal stent was placed due to stenosis associated with endolaryngeal synechia, and decannulation could not be performed as the patient was overstressed and in panic, although the patient's airway was sufficient after removal of the stent. The patient preferred to continue with the tracheotomy.

Table 1. Postoperative complications and problems

\begin{tabular}{|lc|}
\hline Complications / Problems & No. of patients \\
\hline Early post-operative period $(n=58)$ & \\
Aspiration pneumonia & 2 \\
Subcutaneous emphysema & \\
Follow-up period ( $n=56)$ & 9 \\
Granulation tissue/polyps & 2 \\
Laryngeal synechia or stenosis & \\
\hline
\end{tabular}




\section{Functional results}

Decannulation and deglutition occurred within 15 days in two-thirds of patients. Eighty percent of patients could be discharged from hospital within 21 days (Table 2).

Decannulation: All patients were successfully decannulated. The mean decannulation time was $11.8 \pm 7.6$ days (range: 2 to 29 days). While the average decannulation time was $5.1 \pm 2.0$ days in 29 patients who were decannulated early, the average decannulation time was $18.4 \pm 4.7$ days in 29 patients who were decannulated late. In the follow-up period, the patient who could not be decannulated after treatment for laryngeal stenosis was considered as functional failure.

Deglutition: All patients were able to swallow. The nasogastric tube was removed after a mean duration of $15.4 \pm 4.4$ days (range: 8 to 33 days). While the average nasogastric tube removal time was $14.4 \pm 3.1$ days in patients who were decannulated early, the average nasogastric tube removal time was $16.3 \pm 5.2$ days in patients who were decannulated late.

Hospital stay: The mean duration of hospital stay was $19.3 \pm 6.1$ days (range: 10 to 40 days). While the hospitalization period was $16.7 \pm 3.3$ days in patients who were decannulated early, the hospitalization period was $21.8 \pm 7.1$ days in patients who were decannulated late.

When the functional results were analyzed, the mean time for decannulation and hospital stay was significantly decreased in 29 patients who were decannulated early $(p<0.05)$. Preservation of both arytenoids did not significantly reduce these functional parameters ( $p>0.05)$ (Table 3).

Acoustic analysis: The mean Fo was $179.27 \pm 71.32 \mathrm{~Hz}$ and the MPT was $9.1 \pm 4.2$ seconds. Jitter and shimmer averages were $8.10 \pm 5.59$ percent and $16.60 \pm 5.81$ percent, respectively. The mean NHR value was $0.51 \pm 0.23$ (Table 4). The mean Fo

Table 2. Postoperative functional data ( $n=58$ patients)

\begin{tabular}{|lccc|}
\hline \multirow{2}{*}{$\begin{array}{l}\text { Number of } \\
\text { days }\end{array}$} & \multicolumn{3}{c|}{ No. of patients (\%) } \\
\cline { 2 - 4 } & NT* Removal & Decannulation & Hospital stay \\
\hline 10 & $3(5.2)$ & $29(50.0)$ & - \\
$16-15$ & $35(60.3)$ & $10(17.2)$ & $19(32.8)$ \\
$>21$ & $16(27.6)$ & $13(22.4)$ & $27(46.5)$ \\
\hline * NT: nasogastric tube & $4(6.9)$ & $6(10.3)$ & $12(20.7)$ \\
\hline
\end{tabular}

in the patients was higher than that in the control group (140.6 $\mathrm{Hz}$ ). However, the increase in the average Fo was not statistically significant $(p>0.05)$. Mean jitter, shimmer and NHR values in patients with Tucker's operation were significantly increased compared to those in the control group $(p=0.004, p=0.004$ and $p=0.0001$ respectively). In addition, the MPT value in patients significantly shortened $(p<0.05)$ compared to that in the control group (16.4 sec).

Voice Handicap Index: The mean total VHI scores was $25.7 \pm 2.3$ points. The mean of $\mathrm{VHI}$ scores for physical, functional and emotional subscales were 9.3 $\pm 7.4,9.5 \pm 8.3$ and 6.9 9.2 , respectively. The mean $\mathrm{VHI}$-emotional score was lower than the VHI-physical and the VHI-functional values (Table 4).

There was no significant correlation between the acoustic parameters and $\mathrm{VHI}$ scores except for a positive correlation between shimmer and VHI-functional subscale (Table 5). The number of preserved arytenoid cartilages (two arytenoids $=21$ cases; single arytenoid=5 cases) was found to have no impact on either the acoustic analysis or on total $\mathrm{VHI}$ and subscale scores $(p>0.05)$.

Late swallowing and aspiration: The Grade 1 aspiration problem described in seven of the 26 patients was infrequently experienced and only while drinking water.

Table 4. Results of the acoustic voice analysis and voice handicap index scores ( $n=26$ patients)

\begin{tabular}{|lccc|}
\hline Parameters & Mean \pm SD & Median & Range \\
\hline $\begin{array}{l}\text { Maximum } \\
\text { phonation time (sec) }\end{array}$ & $9.1 \pm 4.2$ & 8.5 & $4-18$ \\
$\begin{array}{l}\text { Fundamental } \\
\text { frequency (Hz) }\end{array}$ & $179.27 \pm 71.32$ & 188.67 & $69.15-356.79$ \\
$\begin{array}{l}\text { Jitter (\%) } \\
\text { Shimmer (\%) }\end{array}$ & $8.10 \pm 5.59$ & 5.71 & $1.90-20.49$ \\
$\begin{array}{l}\text { Noise-to-harmonic } \\
\text { ratio }\end{array}$ & $0.51 \pm 0.23$ & 0.52 & $0.16-1.05$ \\
$\begin{array}{l}\text { Voice handicap } \\
\text { index (VHI) }\end{array}$ & $25.7 \pm 2.3$ & 22.5 & $0-100$ \\
$\quad$ VHI-functional & $9.5 \pm 8.3$ & 9 & $0-36$ \\
VHI-physical & $9.3 \pm 7.4$ & 8.5 & $0-24$ \\
$\quad$ VHI-emotional & $6.9 \pm 9.2$ & 4 & $0-40$ \\
\hline
\end{tabular}

Table 3. Analysis of functional parameters ( $n=58$ patients)

\begin{tabular}{|c|c|c|c|c|c|c|}
\hline & \multicolumn{2}{|c|}{ NT* Removal } & \multicolumn{2}{|c|}{ Decannulation } & \multicolumn{2}{|c|}{ Hospital stay } \\
\hline & Days $\pm S D *$ & $p$ value & Days $\pm S D^{*}$ & $p$ value & Days $\pm S D *$ & $p$ value \\
\hline \multicolumn{7}{|l|}{ Arytenoid cartilage resection } \\
\hline One resected $(n=13)$ & $14.2 \pm 2.9$ & \multirow{2}{*}{0.293} & $12.2 \pm 7.4$ & \multirow{2}{*}{0.801} & $18.0 \pm 4.2$ & \multirow{2}{*}{0.396} \\
\hline None resection $(n=45)$ & $15.7 \pm 4.7$ & & $11.6 \pm 7.7$ & & $19.7 \pm 6.5$ & \\
\hline \multicolumn{7}{|l|}{ Decannulation procedure } \\
\hline Late $(n=29)$ & $16.3 \pm 5.2$ & \multirow{2}{*}{0.112} & $18.4 \pm 4.7$ & \multirow{2}{*}{0.0001} & $21.8 \pm 7.1$ & \multirow{2}{*}{0.001} \\
\hline Early $(n=29)$ & $14.4 \pm 3.1$ & & $5.1 \pm 2.0$ & & $16.7 \pm 3.3$ & \\
\hline All patients $(n=58)$ & $15.4 \pm 4.4$ & - & $11.8 \pm 7.6$ & - & $19.3 \pm 6.1$ & - \\
\hline
\end{tabular}




\section{Oncologic Results}

Mean follow-up time was 68.2 months (range, 10-216 months). Two patients did not show up at the follow-up period. Thus, oncologic results could be evaluated in the remaining 56 patients.

Survival: The 5-year and 10-year overall survival rates were $81.5 \%$ and $67.0 \%$, respectively (Figure 1 ). The 5 -year and 10 -year cause-specific survival rates were $96.9 \%$ and $92.3 \%$, respectively (Figure 2). Eleven patients died during the postoperative follow-up period. The causes of death were intercurrent disease (six patients), metachronous second primary cancers (three patients), metastatic disease (one patient), and local recurrence (one patient). Local recurrence, nodal recurrence and positive or close-contiguity surgical margin were significant factors for cause-specific survival (Table 6).

Local and nodal recurrences: Locoregional recurrences occurred in three patients. One patient had local recurrence, one patient had local and nodal recurrence, and one patient had nodal recurrence. The 5-year actuarial local control rate was $95.4 \%$. The locoregional recurrences were noted after a period ranging from 22 to 41 months after the surgery. Two patients, in whom locoregional recurrence developed, had positive or close-contiguity surgical margin. There was no locoregional recurrence in 6 of 8 patients with positive or closecontiguity surgical margins at follow-up. Salvage therapy for

Table 5. Spearman's rho correlation coefficients between acoustic voice analysis parameters and voice handicap index scores

\begin{tabular}{|lcccc|}
\hline & \multicolumn{4}{c|}{ Voice Handicap Index } \\
\cline { 2 - 5 } & Total & Functional & Physical & Emotional \\
$\begin{array}{l}\text { Maximum } \\
\text { phonation time }\end{array}$ & -0.031 & -0.084 & -0.178 & 0.054 \\
$\begin{array}{l}\text { Fundamental } \\
\text { frequency }\end{array}$ & 0.333 & 0.338 & 0.342 & 0.270 \\
Jitter & 0.079 & 0.165 & 0.016 & 0.043 \\
$\begin{array}{l}\text { Shimmer } \\
\text { Noise-to- }\end{array}$ & 0.283 & $0.417^{\star}$ & 0.086 & 0.220 \\
harmonic ratio & 0.160 & 0.247 & 0.073 & 0.062 \\
\hline * $\mathrm{p}=0.048$ & & & & \\
\hline
\end{tabular}

Table 6. $P$ values of the univariate analysis of local recurrence, nodal recurrence, overall and cause-specific survival

\begin{tabular}{|c|c|c|c|c|}
\hline $\begin{array}{l}\text { Independent } \\
\text { factors }\end{array}$ & $\begin{array}{l}\text { Local } \\
\text { recurrence }\end{array}$ & $\begin{array}{l}\text { Nodal } \\
\text { recurrence }\end{array}$ & $\begin{array}{l}\text { Overall } \\
\text { survival }\end{array}$ & $\begin{array}{l}\text { Cause } \\
\text {-specific } \\
\text { survival }\end{array}$ \\
\hline Age & 0.796 & 0.283 & 0.023 & 0.796 \\
\hline $\begin{array}{l}\text { Arytenoid } \\
\text { cartilage resection }\end{array}$ & 0.275 & 0.480 & 0.481 & 0.275 \\
\hline Positive margins & 0.001 & 0.023 & 0.075 & 0.001 \\
\hline $\begin{array}{l}\text { Close-contiguity } \\
\text { margins }\end{array}$ & 0.001 & 0.773 & 0.075 & 0.001 \\
\hline Local recurrence & - & 0.0001 & 0.004 & 0.0001 \\
\hline Nodal recurrence & - & - & 0.275 & 0.0001 \\
\hline
\end{tabular}

a patient with local recurrence was performed via total laryngectomy with postoperative radiotherapy. However, this patient died due to uncontrollable disease. The local recurrence developed in the $28^{\text {th }}$ postoperative month in the patient with locoregional recurrence was controlled via supracricoid partial laryngectomy with cricohyoidopexy. The nodal recurrence, which developed in the $41^{\text {th }}$ postoperative month in this patient, was treated via radiotherapy. This patient died in $64^{\text {th }}$ postoperative month due to metastatic pulmonary disease. A patient with nodal recurrence was treated via radiotherapy.

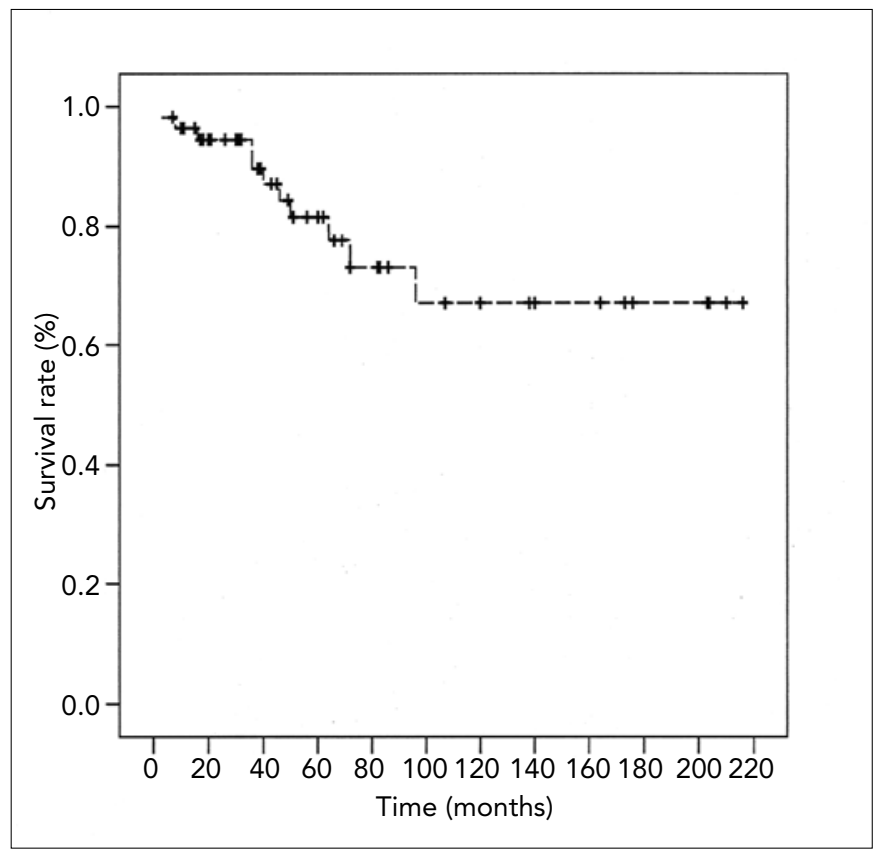

Figure 1. The 5-year and 10-year overall survival rates ( $n=56$ patients)

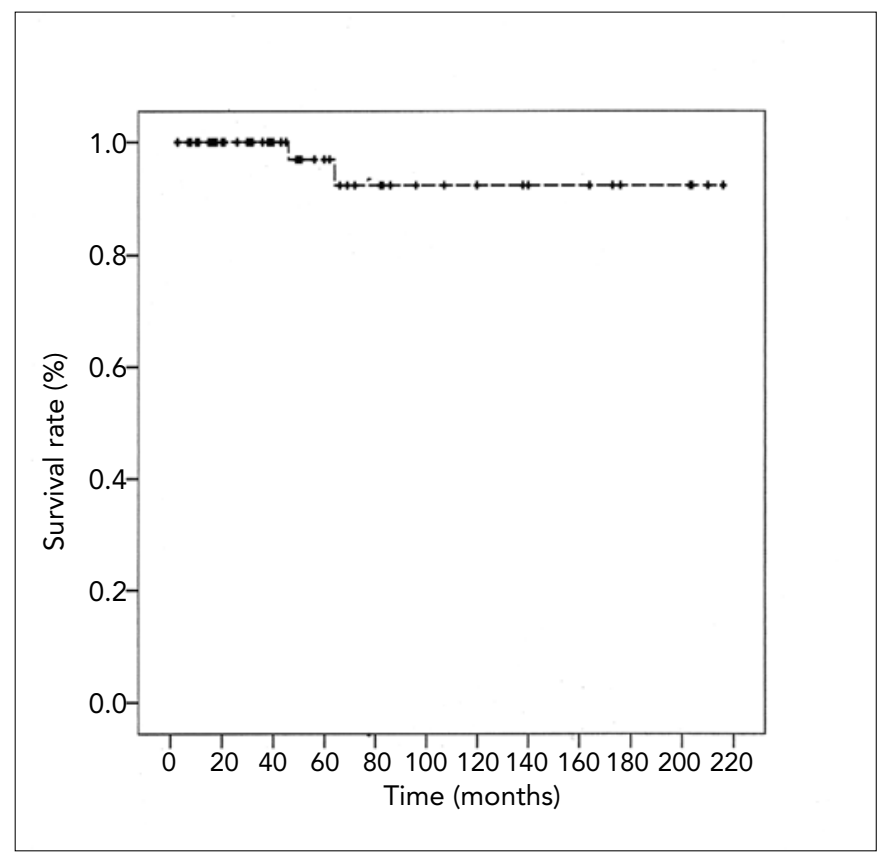

Figure 2. The 5-year and 10-year cause-specific survival rates ( $n=56$ patients) 
The 5-year actuarial nodal control rate was $95.2 \%$. The most important factor affecting local recurrence was a close-contiguity or positive surgical margin. Also, the most important factor influencing nodal recurrence was local recurrence or a positive surgical margin (Table 6).

\section{Discussion}

The surgical approach to be adopted in the treatment of early glottic cancers may vary depending on the tumor localization, its spread and the surgeon's personal experience. Optimal surgical approach for early-stage glottic carcinoma should maintain safe oncologic progress while offering a good functional result that meets the patient's expectations. In order that Tucker's operation can be implemented, the lesion should be a primary glottic tumor allowing for resection, leaving at least one of the arytenoid cartilages intact, the epiglottis should not have an involvement, ventricular involvement should be minimal, subglottic extension should be less than $1 \mathrm{~cm}$, vocal cords should not be fixed and no thyroid cartilage infiltration should be present (4). The patient being over the age of 75 , poor patient cooperation, cardiac or pulmonary disease, presence of arytenoid fixation, subglottic extension being over $1 \mathrm{~cm}$ anteriorly and $0.5 \mathrm{~cm}$ laterally and over-involvement of ventricular folds or anterior commissure are the contraindications for this technique (14). The 5-year local control rates reported in the literature for this technique range between $87 \%$ and $94 \%(5,14,15)$. The 5 -year actuarial local control rate found in our study was $95.4 \%$ and the 5 -year nodal control rate was $95.2 \%$. Obviously, locoregional control rates found in our study were high, with the oncologic inadequacy seen only in 3 patients. Findings of our study also support the data that local control is the most important factor affecting nodal control in glottic tumors (16). The rate of success achieved in locally controlling the tumor in glottic cancers is dependent upon the tumor's anterior commissure and/or its relationship with the paraglottic space and how much the surgical technique to be applied controls such spaces. Anterior commissure and paraglottic space are weak barrier points with regard to the invasion of glottic tumors to thyroid cartilage, due to its anatomical properties $(5,15)$. Tucker's operation bears the risk of oncologic inadequacy in glottic tumors where there is massive anterior commissure involvement, significant ventricle involvement causing thickening in ventricular bands or with posterior ventricular involvement because it does not permit full paraglottic space resection despite permitting "en bloc" anterior commissure resection, and because it is a transcartilaginous technique $(5,14,15)$. In such glottic tumors, our choice is supracricoid partial laryngectomy with cricohyoidoepiglottopexy, which is almost identical in indications but allows full resection of the thyroid cartilage and paraglottic space (2). The 5-year survival rates reported in the literature for this technique ranges between $82 \%$ and $95 \%(5-7,14,15)$. The 5-year overall survival and cause-specific survival rates obtained in our series were $81.5 \%$ and $96.9 \%$, respectively. In the literature, it is emphasized that lymph node recurrence or presence of unclear surgical margin decreases survival $(15,17)$. Two out of 3 patients in our study, who developed oncologic inadequacy (cases who developed local or locoregional recurrence), had positive or close-contiguity surgical margin. The findings of our study show that a positive or close-contiguity surgical margin is the most important factor affecting both local recurrence and nodal recurrence. Moreover, local recurrence, nodal recurrence and positive or close-contiguity surgical margin were found as factors affecting cause-specific survival. Thus, patients with no clear surgical margins need a closer follow-up.

Successful treatmet outcomes by use of transoral laser surgery or radiotherapy for early glottic cancer have been reported. In a series of 163 patients with T1 glottic squamous cell carcinoma who were treated with radiotherapy alone, Nomiya et al. (18) reported a 95.9\% 5-year cause-specific survival rate and a $90.1 \% 5$-year local control rate. In this series, the 5-year cause specific survival and local control rates for patients with T1b tumors were $93 \%$ and $85 \%$, respectively (18). In a current review, it has been highlighted that transoral laser surgery has similar success rates to those obtained by conventional conservation surgery. In addition, transoral laser surgery has better postoperative function and less morbidity (19). Currently, although there is a growing tendency to use transoral laser surgery and radiotherapy as an initial treatment for early laryngeal cancer, anterior commissure involvement should be considered because of the risk of local recurrence of such involvement. In 2009, Rödel et al. (20) who had great experience in transoral laser surgery, reported that anterior commissure involvement caused a decrease in 5-year local control rates (for T1a tumors $73 \%$ vs $89 \%$ and T1b tumors $68 \%$ vs $86 \%$ ). In our practice, the basic selection criterion of patients with T1 glottic tumors for the Tucker operation is the involvement of the anterior commissure. In our series, 11 of 39 patients with T1 glottic tumors had tumors reaching the anterior commissure, while the remaining 28 patients had tumors involving the anterior commissure. The functional target of partial laryngectomy techniques is to make sure that swallowing, speech and respiration are comfortably maintained requiring no permanent tracheotomy. The mean time of the nasogastric tube remova ranged between $12-17$ days $(5,7)$, decannulation time between 6.1-20 days $(7,15)$, and hospitalization time between $16-22$ days $(5,21)$. Our mean functional results werewithin the average time notified in the literature $(5,7,15,21)$. At our clinic, we previously preferred decannulation following no-aspiration swallowing during the swallowing/speech rehabilitation process of open partial laryngectomies in order to minimize the risk of serious pulmonary complications associated with early postoperative aspiration (2). However, after 2003, we revised our approach to the subject, and began to apply the decannulation before the removal of the nasogastric tube. With this approach, there has been a significant improvement in functional results in cases decannulated early without aspiration-induced pulmonary complications. The argument of Laccourreye et al. (22), who suggest that early decannulation is one of the keys to successful swallowing rehabilitation, is clearly supported, from a comparative point of view, by the findings of our study. It was reported that the preservation of both arytenoid cartilages facilitated neoglottic closure, improving the patients' swallowing and vocal functions $(6,23)$. 
Contrary to these reports, we found that the preservation of both arytenoid cartilages had no positive effect on the swallowing, decannulation and hospitalization durations. In our study, the patient who developed endolaryngeal stenosis had been discharged without any problem after Tucker's operation. This patient was intubated because of respiratory arrest due to a heart attack during the follow-up period and had stayed in intensive care unit for a month, and he was retracheotomized. We think that the stenosis in this case was secondary to the long-term intubation and retracheostomy rather than the surgical technique. However, the outcome of this patient was considered as a functional failure. Occasional cough (grade 1 aspiration problem) was described by seven of 26 patients $(26.9 \%)$ who were questioned for late postoperative aspiration. This problem is common after conservation surgery; it may often be encountered with this innocent problem. In one series, grade-I aspiration problem after conservation surgery was reported in approximately half of the cases (7).

In our work, the mean Fo value was $179.27 \pm 71.32 \mathrm{~Hz}$. Although not statistically significant, this value demonstrated an increase. The length, mass, and tension of vocal folds are the main factors determining fundamental frequency (24). It was reported that the Fo value increased with the increase in the resection dimension of anatomic structures at the glottic level $(24,25)$. In our study, mean jitter, shimmer and NHR values were $8.10 \pm 5.59,16.60 \pm 5.81$ and $0.51 \pm 0.23$, respectively. Our acoustic evaluation noted a significant increase in the value of the jitter $(p=0.004)$, shimmer $(p=0.004)$ and NHR $(p=0.0001)$. The mean MPT value of patients was $9.1 \pm 4.2 \mathrm{sec}$, showing a significant reduction $(p=0.001)$. The increase of jitter and shimmer shows aperiodicity in the glottal cycle and an increase in the variation of voice wave amplitude, and NHR analyses the aperiodic components of voice (24).

In our study, self-perceptual voice evaluation showed that the vocal disability scores of patients were on a mild level. Moreover, while the average functional and physical subscale scores similarly showed that the patients had a mild level of vocal disability, the average emotional subscale score was lower. This may be interpreted to mean that the patients were less affected emotionally when using their voices, although they were physically and functionally strained. In the study by Olthoff et al. (26) on total laryngectomy patients with voice prosthesis and patients who underwent partial laryngectomy with transoral laser surgery, both patient groups graded their voices as "well" in the questionnaire performed for evaluation purposes. Therefore, it can be sufficient to have a posttreatment communication language for most patients with larynx cancer. Although acoustic and perceptual measurements are important parameters for the evaluation of vocal function, they provide no information about the patients' perception of their own voice qualities (10). In our study, lack of any significant correlations between the acoustic parameters and VHI scores, except for a positive correlation between shimmer and VHI-functional subscale, is a finding supporting this datum. Findings of this study also showed that the number of preserved arytenoid cartilages had no effect on either acoustic analysis or on total $\mathrm{VHI}$ and subscale scores. Although not considered within the scope of this study, it is quite important to have a communication language with "intelligible speech". As an organ-preserving surgery, the Tucker's procedure also offers a communication language with intelligible speech. Although the oncologic results and early postoperative functional results have been evaluated in almost all patients, the late functional results could be evaluated in $44.8 \%$ of the patients in the present study. Thus, late functional results should be interpreted from that aspect.

In conclusion, Tucker's operation is an effective procedure in the treatment of glottic laryngeal carcinomas when anterior commissure resection is needed. As a single-stage technique, it has satisfactory functional results and high oncologic success rates.

\section{Conflict of Interest}

No conflict of interest was declared by the authors.

\section{References}

1. Back G, Sood S. The management of early laryngeal cancer: options for patients and therapists. Curr Opin Otolaryngol Head Neck Surg 2005;13:85-91. [CrossRef]

2. Karasalihoglu AR, Yagiz R, Tas A, Uzun C, Adali MK, Koten M. Supracricoid partial laryngectomy with cricohyoidopexy and cricohyoidoepiglottopexy: functional and oncological results. J Laryngol Otol 2004;118:671-5. [CrossRef]

3. Tucker HM, Wood BG, Levine H, Katz R. Glottic reconstruction after near total laryngectomy. Laryngoscope 1979;89:609-18. [CrossRef]

4. Tucker HM, Benninger MS, Roberts JK, Wood BG, Levine $\mathrm{HL}$. Near-total laryngectomy with epiglottic reconstruction. Long-term results. Arch Otolaryngol Head Neck Surg 1989;115:1341-4. [CrossRef]

5. Mallet Y, Chevalier D, Darras JA, Wiel E, Desaulty A. Near total laryngectomy with epiglottic reconstruction. Our experience of 65 cases. Eur Arch Otorhinolaryngol 2001;258:488-91. [CrossRef]

6. Lawson G, Jamart J, Remacle M. Improving the functional outcome of Tucker's reconstructive laryngectomy. Head Neck 2001;23:871-8. [CrossRef]

7. Oysu C, Aslan I. Cricohyoidoepiglottopexy vs near-total laryngectomy with epiglottic reconstruction in the treatment of early glottic carcinoma. Arch Otolaryngol Head Neck Surg 2006;132:1065-8. [CrossRef]

8. Jacobson BH, Johnson A, Grywalski C, Silbergleit A, Jacobson $\mathrm{G}$, Benninger MS, et al. The Voice Handicap Index (VHI) development and validation. Am J Speech Lang Pathol 1997;6:66-70.

9. Kiliç MA, Okur E, Yildirim I, Oğüt F, Denizoğlu I, Kizilay A, et al. Reliability and validity of the Turkish version of the Voice Handicap Index . Kulak Burun Bogaz Ihtis Derg 2008;18:139-47.

10. Núñez Batalla F, Caminero Cueva MJ, Señaris González B, Llorente Pendás JL, Gorriz Gil C, López Llames A, et al. Voice quality after endoscopic laser surgery and radiotherapy for early glottic cancer: objective measurements emphasizing the Voice Handicap Index. Eur Arch Otorhinolaryngol 2008;265:543-8. [CrossRef]

11. Ciftci E. Late functional evaluation after supracricoid partial laryngectomy [master's thesis]. Edirne, Medical Faculty, Trakya University; 2009.

12. Leipzig B. Neoglottic reconstruction following total laryngectomy. A reappraisal. Ann Otol Rhinol Laryngol 1980;89:534-7.

13. Pearson BW. Subtotal laryngectomy. Laryngoscope 1981;91: 1904-12. [CrossRef]

14. Zanaret M, Giovanni A, Gras R, Bonnefille E, Robert D, Cannoni $M$. Reconstructive anterior frontal laryngectomy. Long-term re- 
sults in T2 glottic cancers. Ann Otolaryngol Chir Cervicofac 1995;112:205-10.

15. Bakhos $D$, Lescanne $E$, Beutter $P$, Morinière $S$. Indications of cricohyoidoepiglottopexy versus anterior frontal laryngectomy: the role of contralateral vocal fold spread. Head Neck 2008;30: 1408-14. [CrossRef]

16. Chevalier D, Laccourreye O, Brasnu D, Laccourreye H, Piquet JJ. Cricohyoidoepiglottopexy for glottic carcinoma with fixation or impaired motion of the true vocal cord: 5-year oncologic results with 112 patients. Ann Otol Rhinol Laryngol 1997;106:364-9.

17. Bron L, Brossard E, Monnier P, Pasche P. Supracricoid partial laryngectomy with cricohyoidoepiglottopexy and cricohyoidopexy for glottic and supraglottic carcinomas. Laryngoscope 2000;110:627-34. [CrossRef]

18. Nomiya T, Nemoto K, Wada H, Takai Y, Yamada S. Long-term results of radiotherapy for $\mathrm{T} 1 \mathrm{a}$ and $\mathrm{T} 1 \mathrm{bNOMO}$ glottic carcinoma. Laryngoscope 2008;118:1417-21. [CrossRef]

19. Silver CE, Beitler JJ, Shaha AR, Rinaldo A, Ferlito A. Current trends in initial management of laryngeal cancer: the declining use of open surgery. Eur Arch Otorhinolaryngol 2009;266: 1333-52. [CrossRef]

20. Rödel RM, Steiner W, Müller RM, Kron M, Matthias C. Endoscopic laser surgery of early glottic cancer: involvement of the anterior commissure. Head Neck 2009;31:583-92. [CrossRef]
21. Lelièvre G, Laccourreye $O$, Strunski $V$, Juvanon JM, Bedbeder $P$, Peynegre R. Critical study and role of partial vertical reconstructive laryngectomies with epiglottoplasty by the Tucker method. Apropos of 18 cases. Ann Otolaryngol Chir Cervicofac 1987; 104:323-8. [CrossRef]

22. Laccourreye $O$, Brasnu D, Merite-Drancy A, Cauchois $R$, Chabardes E, Ménard $M$, et al. Cricohyoidopexy in selected infrahyoid epiglottic carcinomas presenting with pathological preepiglottic space invasion. Arch Otolaryngol Head Neck Surg 1993;119:881-6.

23. Giovanni A, Guelfucci B, Gras R, Yu P, Zanaret M. Partial frontolateral laryngectomy with epiglottic reconstruction for management of early-stage glottic carcinoma. Laryngoscope 2001;111:663-8. [CrossRef]

24. Haddad L, Abrahão M, Cervantes O, Ceccon FP, Gielow I, Carvalho $\mathrm{JR}$, et al. Vocal assessment in patients submited to $\mathrm{CO} 2$ laser cordectomy. Braz J Otorhinolaryngol 2006;72:295-301.

25. Modrzejewski M, Olszewski E, Wszołek W, Reroń E, Strek P. Acoustic assessment of voice signal deformation after partial surgery of the larynx. Auris Nasus Larynx 1999;26:183-90. [CrossRef]

26. Olthoff A, Mrugalla S, Laskawi R, Fröhlich M, Stuermer I, Kruse $\mathrm{E}$, et al. Assessment of irregular voices after total and laser surgical partial laryngectomy. Arch Otolaryngol Head Neck Surg 2003;129:994-9. [CrossRef] 